\title{
Editorial. Antiterrorisme et société
}

\section{(2) OpenEdition \\ 1 Journals}

Édition électronique

URL : http://journals.openedition.org/conflits/2033

DOI : $10.4000 /$ conflits.2033

ISSN : $1777-5345$

Éditeur :

CCLS - Centre d'études sur les conflits lilberté et sécurité, L'Harmattan

Édition imprimée

Date de publication : 1 mars 2006

Pagination : 5-7

ISBN : 2-296-00622-1

ISSN : 1157-996X

Référence électronique

«Editorial. Antiterrorisme et société », Cultures \& Conflits [En ligne], 61 I printemps 2006, mis en ligne le 17 mai 2006, consulté le 30 mars 2021. URL : http://journals.openedition.org/conflits/2033 ; DOI :

https://doi.org/10.4000/conflits.2033

Ce document a été généré automatiquement le 30 mars 2021.

Creative Commons License 


\section{Editorial. Antiterrorisme et société}

1 Ce nouveau numéro de Cultures \& Conflits sur «antiterrorisme et société " est le troisième et dernier volet de la publication des travaux issus du programme-cadre de recherche ELISE ${ }^{1}$ qui se prolonge maintenant sous le nom de CHALLENGE. Ce numéro est l'occasion pour nous de revenir plus amplement à la fois sur les implications de la logique militaire de la guerre au terrorisme que nous avions évoquées dans le numéro «Défense et identités. Un contexte sécuritaire global ${ }^{2}$ ? » et sur le statut même de la guerre dans le monde contemporain lorsqu'on applique ce terme de guerre à la violence politique qui traverse les régimes libéraux et s'inscrit dans leurs relations à l'autre.

2 Cette analyse des figures contemporaines de la guerre poursuit la recherche initiée dans le premier volet de la présentation des travaux du programme ELISE, publiée dans le numéro 56 de la revue, intitulé « Militaires et sécurité intérieure. L'Irlande du nord comme métaphore ${ }^{3}$ ", un numéro où nous nous proposions d'analyser ces moments où les militaires veulent faire retour sur l'interne et la protection des frontières, au nom de la lutte contre la violence politique d'une organisation clandestine. Le deuxième volet avait trait à l'approfondissement des logiques de "suspicion et [d']exception ${ }^{4}$ ». Nous avions publié les contributions des chercheurs de l'Université de Nijmegen (PaysBas) et de l'Université de Keele (Royaume-Uni) sur ce thème. Ce numéro poursuivait à sa manière la réflexion engagée précédemment sur les logiques, les dispositifs et les stratégies antiterroristes à l'œuvre en Europe et aux Etats-Unis. Véritable numéro charnière de la recherche menée dans le programme ELISE, celui-ci visait l'exploration de ces moments où, sous le coup d'une violence disruptive, l'inclinaison vers les raisonnements du scénario du pire produit un climat de suspicion justifiant le recours à des dérogations en matière de libertés publiques et de droits de l'Homme. Nous cherchons avec ce numéro à approfondir encore davantage l'impact de ces formes d'exception qui se parent des figures de la guerre, et disent répondre à la violence par une coercition et une surveillance renforcées. Il y a sans doute à réfléchir sur le niveau approprié de réponse à la violence politique, et nous l'avons fait depuis longtemps, en nous demandant si ces formes de violences mettent en jeu ou non la survie de l'Etat ${ }^{5}$, et ce qui se passe quand les discours et figures de guerre se surimposent à ces logiques et se veulent explicatives du moment. 
Quand les inquiétudes politiques génèrent des solutions parfois plus dramatiques que les maux auxquels elles sont supposées apporter raison; quand les rhétoriques d'une menace diffuse et prégnante prennent le pas sur les analyses circonstanciées et minutieuses; quand les politiques d'exception font appel à un discours de légitimation fondé sur la prévention et la préemption; quand, en définitive, la guerre devient la solution la plus évidente, qu'advient-il in fine de nos traditions libérales et démocratiques qui étaient au cœur de ce qu'il fallait protéger de la violence des organisations clandestines? Vivienne Jabri montre très clairement comme la guerre imprègne la normalité de nos processus politiques et refonde ainsi les conceptions classiques de l'Etat libéral. Dans son analyse des discours de justification des mesures dérogatoires et restrictives aux libertés publiques en France, en Italie et au Royaume-Uni, Anastassia Tsoukala montre, quant à elle, comment cette introduction d'une certaine figure de la guerre rend possible la justification de cette diminution des droits fondamentaux. La vulnérabilité de toute démocratie supposerait donc l'établissement d'une meilleure politique de sécurité où les libertés seraient occultées au nom de l'éradication de la menace terroriste. Dans son article, Emmanuel-Pierre Guittet discute ce discours politique européen visant à l'établissement d'une meilleure politique de sécurité commune fondée sur une meilleure coopération en matière de lutte antiterroriste, et montre comment le référent démocratique permet de recouvrir l'illégalité suivant une politique d'amnésie qui convertit le plomb de la coopération en or de la qualité démocratique de l'Etat de droit. En revenant pas à pas sur l'histoire de l'infraction politique dans le droit belge, Martin Moucheron montre comment la dépolitisation des actes et/ou des auteurs qualifiés de "terroristes" et donc de ce passage de l'appréciation à la dépréciation de l'intention politique participe de la reconfiguration des règles de l'Etat libéral démocratique.

\section{NOTES}

1.. ELISE, European Liberty and Security, est un programme de recherche de type PCRD (5 génération) financé par la Commission européenne. Il regroupe depuis octobre 2002 sept universités européennes dont l'Institut d'Etudes Politiques de Paris (France) et le King's College (Royaume-Uni) dont nous publions ici les contributions.

2.. «Défense et identités. Un contexte sécuritaire global ? », Cultures \& Conflits, $\mathrm{n}^{\circ} 44$, hiver 2001, $172 \mathrm{p}$.

3.. " Militaires et sécurité intérieure. L'Irlande du Nord comme métaphore », Cultures \& Conflits, $\mathrm{n}^{\circ} 56$, hiver 2004, 264 p.

4.. « Suspicion et exception », Cultures \& Conflits n58, été 2005, 220 p.

5.. Chocquet $\mathrm{C}$., « Le terrorisme est-il une menace de défense ? », Cultures \& Conflits, $\mathrm{n}^{\circ} 44$, hiver 2001, pp. 19-64. 
INDEX

Mots-clés : anti-terrorisme 